employed to improve processes in the absence of more sophisticated technological solutions. A staff survey is planned to evaluate awareness and usability of the database and identify further areas for improvement.

\section{P59 ASSESSING MEDICINES FOR SAFE USE IN PAEDIATRICS}

Mary Worrall ${ }^{*}$, Anne Fitzpatrick. Children's Health Ireland, Crumlin

10.1136/archdischild-2020-NPPG.67

Aim This service review aimed to reassess and upgrade the 'New Products Assessment Form' and to develop an assessment tool in line with European regulations governing paediatric medicines. Many medicinal products routinely used to treat the paediatric population have not been studied or authorised for paediatric use, which means there is widespread unlicensed and 'off-label' use of medicines. Medicines deemed safe in adult formulations may not be appropriate for paediatric patients. Medicines must therefore be carefully selected based on agreed criteria including, but not limited to: licensing, excipients, administration, labelling, similarity to other products, safety and handling.

Method A literature review was conducted. Guidance, information, and advice was sought from other healthcare institutions, and European guidelines and directives informing current practise around excipients in paediatric medicines. Pharmacy colleagues were consulted during the development of the tool, and an accessible assessment tool was completed for use in a tertiary paediatric hospital. ${ }^{1-4}$

Results This is the first comprehensive 'New Products Assessment Form' in the hospital which complies with the European Medicines Agency (EMA) directives governing excipients in paediatric medicines. The document highlights clearly potential issues and risks associated with product excipients, licensing status, warning label guidance and allows for recording of rationale for the selection of medicines. The 'New Products Assessment Form' is intended to highlight potential issues associated with excipients and their associated acceptable daily intake (ADI), but it will also highlight other risks associated with medicines used in paediatrics e.g. inadequate labelling, translation requirements for foreign products, sound-alike/look-alike products, safety and handling, and others.

Conclusion This revised assessment tool has been approved for use in the hospital pharmacy. It will be made available in hospital and community pharmacies on request. Use of the tool should be monitored and audited.

\section{REFERENCES}

1. Annex to the European Commission quideline on 'Excipients in the labelling and package leaflet of medicinal products for human use' (SANTE-2017-11668). https://www.ema.europa.eu/en/documents/scientific-guideline/annex-european-commission-guideline-excipients-labelling-package-leaflet-medicinal-productshuman_en.pdf

2. NPPG Neonatal and Paediatric Pharmacists Group Newsletter No 61 Autumn 2016. Excipients in medicines for children. http://nppg.org.uk/wp-content/uploads/ 2017/04/NPPG-61.pdf

3. Questions and Answers on Ethanol in the context of the revision of the guideline on 'Excipients in the label and package leaflet of medicinal products for human use' (CPMP/463/00) https://www.ema.europa.eu/en/documents/scientific-guideline/ questions-answers-ethanol-context-revision-guideline-excipients-label-package-leaflet-medicinal_en.pdf

4. EMA. Guideline on pharmaceutical development of medicines for paediatric use. https://www.ema.europa.eu/en/documents/scientific-guideline/guideline-pharmaceutical-development-medicines-paediatric-use_en.pdf

\section{P60 EFFICACY OF SWITCHING TO INFLIXIMAB BIOSIMILAR (REMSIMA $^{\circledR}$ ) IN PAEDIATRIC INFLAMMATORY BOWEL DISEASE (PIBD): A 2-YEAR RETROSPECTIVE EVALUATION}

${ }^{1}$ Fatima Yaqub*, ${ }^{2}$ Joanne Crook, ${ }^{2}$ John Fell. ${ }^{1}$ Imperial College London; ${ }^{2}$ Chelsea and Westminster Hospitals NHS Trust, London

10.1136/archdischild-2020-NPPG.68

Aim To evaluate patient outcomes 2 years post switching Infliximab therapy from Infliximab originator molecule Remicade $^{\circledR}$ to biosimilar Remsima ${ }^{\circledR}$.

Methods Patients with PIBD who experienced induction with Remicade $^{\circledR}$ therapy, were $<18$ years old at last follow-up and were receiving active treatment with Remsima ${ }^{\circledR} 2$ years post switching were selected to be included for evaluation. Outcome measures included monitoring disease activity and treatment failure at baseline (before switching) and at selected time points up to 2 years post-switch. Disease activity was assessed looking at a range of parameters: disease activity scores; trough infliximab levels; haematological markers (HGB, platelets, WBC); LFTs (bilirubin, ALT, ALP); inflammatory markers (ESR, CRP) and faecal calprotectin levels. Patients who failed therapy were assessed for adverse reactions and infliximab antibody formation. Data was analysed with the Cochran Q test, repeated measures ANOVA test and Friedman test; with post-hoc Bonferroni and Wilcoxon Signed-Ranks tests if appropriate.

Results Data was available for 18 patients after exclusion criteria were applied. There was a significant increase in trough infliximab levels by the end of the period from an average of $5 \mathrm{ug} / \mathrm{L}$ to $12 \mathrm{ug} / \mathrm{L}$ at 2 years. The average dose $/ \mathrm{kg}$ increased over 2 years by $1.5 \mathrm{mg} / \mathrm{kg}$. Disease activity markers showed no changes between time points except a decrease in ALP levels from baseline to 1 year, but values remained within normal ranges. Four patients were discontinued from Remsima ${ }^{\circledR}$ due to side effects or loss of efficacy. The average time to treatment failure on Remsima $^{\circledR}$ was 38 months $(\sim 19 / 20$ doses). Three out of four patients developed infliximab antibodies, 2 of these patients went on to suffer adverse reactions; 1 exhibited joint pain which settled weeks after each infusion and the other developed an immediate infusion reaction in the form of a rash with urticaria on the 3rd infusion of Remsima ${ }^{\circledR}$.

Conclusion Infliximab biosimilars, such as Remsima ${ }^{\circledR}$, were approved for use in PIBD by the EMA after studies in adult populations with rheumatic diseases. ${ }^{1} 2$ Induction studies have shown efficacy in PIBD but data on switching is limited and short-term. ${ }^{3} 4$ Our data shows no significant differences in clinical patient outcomes over a 2-year period in a cohort switched from Remicade ${ }^{\circledR}$ to Remsima ${ }^{\circledR}$. In fact, a significant increase in trough infliximab levels in patients remaining on Remsima ${ }^{\circledR}$ suggests efficacy in producing therapeutic levels in PIBD patients. Increased levels may be explained by dose intensification used by the PIBD multi-disciplinary team (MDT), reflecting careful dose optimisation strategies used at this trust throughout the time period. Patients losing response were not unexpected and are likely not due to the biosimilar switch but rather due to the length of time the patients were on treatment. The small sample size and retrospective nature of this study mean larger cohort studies are required over prolonged time periods to confirm these findings. PIBD MDTs should continue to monitor patients for adverse reactions, particularly in those who develop infliximab antibodies. 